\title{
EU biosciences panel
}

European Commissioner for Research Philippe Busquin has appointed 11 European scientists from different public research institutes to be part of the Biosciences High Level Group (BHLG), a new advisory body that will represent the EU bioscience research community in dialogs with the public. According to Axel Kahn, chair of BHLG and a senior scientist at the Cochin Molecular Genetics Institute (Paris), the group aims to involve the European Parliament and Council, consumers, nongovernmental organizations, industry, and the media in addressing controversies linked to advances in life sciences. Creation of BHLG is in line with Busquin's proposal to create a unified European Research Policy across the EU that pays special attention to citizens' expectations and demands.

The 1999 Eurobarometer opinion poll on public attitude to biotechnology revealed only $11 \%$ of respondents felt adequately informed about biotechnology.

\section{Eco-terrorism penalties}

Legislation that would impose tough penalties on eco-terrorists guilty of destroying GM research crops was passed by a California committee in April. In the past year, antibiotech group Reclaim the Seeds has claimed responsibility for damage to crops and equipment owned by University of California, Pioneer Hi-Bred, and NK Seeds (Nat. Biotechnol. 17, 1053, 1999), but those responsible have not been caught. Under the new legislation, those actually caught damaging crops would be liable for twice the value of the crop, including the cost of related testing, research, and crop development-as determined by the court. No other state or country has passed anti-GM crop destruction laws, according to the office of State Assemblywoman Helen Thomson (DDavis), who introduced the legislation. The new law, which covers only university research and would impose the same penalties for destruction of livestock, awaits a vote by the entire legislature.

EN

\section{EPA rejects Greenpeace}

On April 20, the US Environmental Protection Agency (EPA; Washington, DC) rejected a petition filed by the environmental group Greenpeace in January calling for the revocation of current licenses for $B t$ transgenic crops. The day before EPA's announcement, anticipating the rejection, Greenpeace released a report criticizing the research EPA subsequently cited in defending the licensing process, claiming that the agency "acknowledges that $B t$ crops could pose risks to monarch butterflies." Although the EPA did refer to additional research done since the original licenses were granted, including a highly publicized laboratory study that suggested that pollen from $B t$ transgenic corn might be harmful to monarch butterfly larvae
(Nat. Biotechnol. 17, 627, 1999), an EPA source familiar with the situation said that that study was cited only to explain voluntary measures implemented in 2000 to reduce butterfly exposure to $B t$ crop pollen while field studies continue. Despite the apparent misinterpretation, Ellen Kramer, an EPA spokesperson, says the agency does not plan to engage in a public relations battle with Greenpeace.

The petition was part of a lawsuit filed against EPA by Greenpeace in $1999 . \quad A D$

\section{India okays Bt cotton}

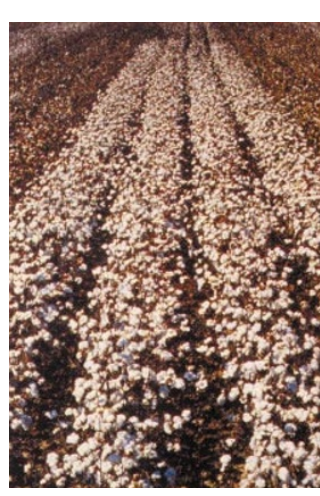

For the first time, the Indian government's Department of Biotechnology (DBT) has granted "biosafety clearance" to genetically modified crop. On April 3, the DBT strongly recommended that Monsanto's

Bt cotton, which has been engineered to contain a gene from Bacillus thuringiensis $(B t)$, should be introduced into the country in the interest of cotton farmers, who have been losing the battle against bollworm, a major pest of cotton. The decision was made after regulators were "fully convinced about its safety and potential economic benefits to farmers," according to DBT adviser Prasantha Ghosh, who says it paves the way for large-scale cultivation and marketing of transgenic cotton in India, and opens the doors for the entry of other GM crops. Monsanto must now go through the formality of seeking permission from the Genetic Engineering Approval Committee for large-scale trials.

\section{Human fly bites rub Celera}

When news surfaced in April that the recently published genome sequence of the fly Drosophila melanogaster was contaminated with human gene sequences, Celera (Rockville, MD), which produced the sequence, immediately removed the affected portions of data from its web site and began correcting the errors. Biologists generally agree that the scientific significance of the contamination in the initial sequence is trivial, but that did not stop researchers from the competing publicly financed Human Genome Project (HGP) from openly criticizing Celera for sloppiness. Celera spokesperson Heather Kowalski suggested that reporters at the Los Angeles Times, which broke the story to the general public, had "some kind of axe to grind with us, and [we] don't believe that this was any kind of a story at all." Kowalski adds that "it's kind of hard for us to ponder. . . why people want to do us harm or say bad things about us." The answer could lie in the ongoing acrimony between the competing genome sequencing efforts: Earlier in April, Celera President Craig Venter told members of Congress that the HGP might be producing shoddy data in its effort to win the sequencing race.

$A D$

\section{EU's new orphan drug regulations}

On April 27, the European Commission implemented the first community-wide orphan drug regulations to encourage development of drugs for diseases affecting less than 5 out of every 10,000 of the EU population. Incentives include a 6- to 10-year period of market exclusivity and exemptions from marketapproval fees, which can amount to more than $£ 100,000$ (US $\$ 150,000$ ). A newly created independent Committee for Orphan Medicinal Products will assess a drug candidate's eligibility for orphan status before submission to the European Medicines Evaluation Agency (EMEA), which regulates the approval of all drugs in the EU. The EMEA says that 31 companies have already expressed an interest in applying for the orphan status designation.

Orphan drug regulation has been in effect in the US since 1983 and has been implemented subsequently in Japan, Australia, and Singapore. 